\title{
First report of rust caused by Coleosporium zanthoxyli on Zanthoxylum piperitum in Korea
}

\author{
Young-Joon Choi ${ }^{1} \cdot$ Jae-Sung Lee ${ }^{1} \cdot$ In-Young Choi ${ }^{2} \cdot$ Hyeon-Dong Shin ${ }^{3}$
}

Received: 28 February 2021 / Accepted: 8 April 2021 / Published online: 14 April 2021

(c) Società Italiana di Patologia Vegetale (S.I.Pa.V.) 2021

Keyword Fish soup · Rutaceae · Urediniospore

Zanthoxylum piperitum (L.) DC. (Japanese pepper) is a deciduous, aromatic, spiny shrub of the Rutaceae family. It is cultivated for harvesting fruits which are used as a condiment for fish soups and stews in Korea. In September 2016, approximately 50\% of the shrub were found affected by a rust in Seoguipo, Korea. Orange-yellow rust pustules were formed on the leaves, causing early defoliation and poor growth. Similar symptoms and signs of rust infection on about $80 \%$ of the shrubs were also found in Jeju in October 2017. Two voucher specimens have been deposited in the Korea University herbarium (KUS), Seoul, Korea. Uredinia were hypophyllous, circularly gregarious or scattered, orange-yellow, erumpent, and up to $600 \mu \mathrm{m}$ in diameter. Urediniospores were subglobose to ellipsoid, $20-40 \times 16-26 \mu \mathrm{m}$, and verrucose. The telial stage was not found. These morphological characteristics were in agreement with those of Coleosporium zanthoxyli Dietel \& P. Syd. (Hiratsuka et al. 1992). To confirm the morphological identification, genomic DNA was extracted from urediniospores taken from two dried herbarium specimens, KUS-F29470 and F30013. PCR amplifications were performed for the internal transcribed spacer (ITS) and large subunit (LSU) rDNA, using specific primer pairs ITS5u/ITS4rust and universal primers LR0R/LR6, respectively (Beenken et al. 2017). PCR products were sequenced and deposited in GenBank (accession Nos. MK530182 and MK530183 for ITS; MK530184 and MK530185 for LSU). A BLASTn search revealed that the sequences share high nucleotide similarities of 99 to $100 \%$

Hyeon-Dong Shin

hdshin@korea.ac.kr

1 Department of Biology, Kunsan National University, Gunsan 54150, Korea

2 Department of Agricultural Biology, Department of Agricultural Convergence Technology, Jeonbuk National University, Jeonju 54896, Korea

3 Division of Environmental Science and Ecological Engineering, Korea University, Seoul 02841, Korea with the ITS (GenBank accession Nos. KX386018, KX386019, MG561459, MG561460) and LSU sequences (KX386049, KX386050, KX386051) of C. zanthoxyli on Zanthoxylum spp. C. zanthoxyli has been reported on 24 species/varieties of Zanthoxylum from China, India, Japan, Korea, Taiwan, and Vietnam. However, to our knowledge, this is the first report of $C$. zanthoxyli on Z. piperitum in Korea (Farr and Rossman 2021).

Acknowledgements This work was supported by a National Academy of Agricultural Science grant [PJ0149560112020] from the Rural Development Administration, Korea.

\section{Declarations}

Informed consent The manuscript is new and not being considered elsewhere. All authors have approved the submission of this manuscript.

Conflict of interest The authors have no conflict of interest to declare.

Research involving human participants and/or animals The authors declare that no human participants and animals were involved in this study.

\section{References}

Beenken L, Lutz M, Scholler M (2017) DNA barcoding and phylogenetic analyses of the genus Coleosporium (Pucciniales) reveal that the North American goldenrod rust $C$. solidaginis is a neomycete on introduced and native Solidago species in Europe. Mycol Prog 16:1073-1085

Farr DF, Rossman AY (2021) Fungal databases, syst. Microbiol. Lab., Online publication. ARS, USDA, Mycol

Hiratsuka N, Sato S, Katsuya K et al (1992) The rust flora of Japan. Tsukuba Shuppankai, Tsukuba, Japan

Publisher's Note Springer Nature remains neutral with regard to jurisdictional claims in published maps and institutional affiliations. 